\title{
EMOTION: APPRAISAL-COPING MODEL FOR THE "CASCADES" PROBLEM
}

\author{
Karim Mahboub $^{(1)}$, Evelyne Clément ${ }^{(2)}$, Cyrille Bertelle ${ }^{(1)} \&$ Véronique Jay ${ }^{(1)}$ \\ ${ }^{(1)}$ LITIS Laboratory, University of Le Havre \\ 25, rue Philippe Lebon, BP 54076058 Le Havre Cedex, France \\ Karim.Mahboub@litislab.eu \\ Cyrille.Bertelle@litislab.eu \\ Veronique.Jay@litislab.eu \\ ${ }^{(2)}$ Psy.CO Laboratory, University of Rouen \\ Rue Lavoisier 76821 Mont-Saint-Aignan, France \\ Evelyne.Clement@univ-rouen.fr
}

\begin{abstract}
Modelling emotion has become a challenge nowadays. Therefore, several models have been produced in order to express human emotional activity. However, only a few of them are currently able to express the close relationship existing between emotion and cognition. An appraisal-coping model is presented here, with the aim to simulate the emotional impact caused by the evaluation of a particular situation (appraisal), along with the consequent cognitive reaction intended to face the situation (coping). This model is applied to the "Cascades" problem, a small arithmetical exercice designed for ten-year-old pupils. The goal is to create a model corresponding to a child's behaviour when solving the problem using his own strategies.
\end{abstract}

Keywords: emotion modelling, decision making, appraisal-coping model.

\section{INTRODUCTION}

As the study of emotion is becoming crucial today, in several fields of study such as neurology or psychology, computer science is getting more and more involved in the process of finding new models for representing emotions. Since the middle of the 19th century, psychologists, biologists, but also neurologists have tried to produce models designed to unravel the emotional processes. Scientists like Bechara and Damasio [3] have even proved that human emotional activity has an indispensable impact on decision making.

The aim of this article is to globally draw the picture of the latest models of emotion in computer science, starting from a psychologist point of view. The appraisalcoping model will be presented more precisely, as well as an existing application example. Afterwards, we will present a small toy problem illustrating a decision making problem, using the appraisal-coping strategy. Eventually, a small conclusion will introduce future aspects to be developped and other prospects.

\section{STATE OF THE ART}

From the most recent approaches of emotion modelling, two major cognitive types of research models have been developed: hierarchical and componential models (see Baudic \& Duchamp, 2006 [1]).

According to the hierarchical approach, emotions have their origin from early stages of development. Indeed, emotions are hierarchically organised with numerous discrete emotions at a basic level and emotional dimensions at a higher level. Fundamental emotions like thirst or fear are elements intended to build more sophisticated emotions, ending up with very complex feelings such as jealousy or pride [7. Emotions at the basic level have an important adaptive function and are directly linked to the body stimuli and effectors.

In componential models, emotions have qualitatively different facets 23]. The so-called "emotional response triad" is composed of the three main components for the emotion production: subjective experience, peripheral physiological responses and motor expression, to which some theorists include two other components, cognitive and motivational. The componential approach deals with the relative role assigned to each of these components. Then, emotions are created by stepping through all parts of the process, from the cognitive perception, until the actual response. Lazarus [13] and Scherer [20] are usually associated with this approach.

\section{APPRAISAL THEORIES}

Appraisal theories suggest that emotion is the result of underlying mechanisms including the subjective evaluation of the significance of a situation and its organism circumstances (appraisal), and the coping mechanisms that guide and provide adaptive responses (Frijda, 1986 [9]; Lazarus, 1991 [14]; Scherer, 1984 [20]; Scherer, 
Schorr \& Johnstone, 2001 24]; Smith \& Lazarus, 1990 [26], 1993 [27]). As noted by Gratch and Marsella [10]: "Appraisal theories posit that events do not have significance in of themselves, but only by virtue of their interpretation in the context of an individual's beliefs, desires, intentions and abilities" (Gratch \& Marsella, 2004, p. 273). The significance of an event is supposed to be evaluated on a number of criteria such as its relevance for one's well-being, its conduciveness for one's plans and goals, and the ability to cope with such consequences.

In the framework of the Scherer's Component Process Model (Scherer 1984 [20], 2001 [24]), Sander, Grandjean \& Scherer (2005 [19]) describe emotion "as an episode of interrelated, synchronized changes in the states of all or most of the five organismic subsystems 1 in response to the evaluation of an external or internal stimulus event as relevant to major concerns of the organism.", (p.318). From this point of view, rather than static and basic states of the organism (e.g. Ekman, 1984 [8] Izard, 1971 [11]), emotions are a dynamic process whose components are the cognitive component which function is the evaluation of objects and events, the peripheral efference component which regulates the system, the motivational component which prepares and guides the actions, the motor expression component which steadies communication of reaction and behavioural intention, and the subjective feeling component which monitors the internal state and environment interaction. In other respects, this model postulates that changes in one subsystem will tend to elicit related changes in other subsystems.

\section{APPRAISAL-COPING EXAMPLE}

Based on the appraisal-coping approach, several new models have been conceived (see figure 1). Gratch \& Marsella [10] have produced a domain independent model using cognitive maps. This model is intended to manipulate appraisal variables to analyse the present and past situations, and to design the future decisions to make and the coping strategies to adopt. Generally speaking, the appraisal-coping approach offers a very precise model of cognitive and emotional processes in decision making (previous works have been carried out on this subject, see [16]).

On the one hand, the environment is appraised with respect to one's goals and beliefs. This evaluation is realised through a certain number of variables defining the different appraising dimensions to be taken into account, such as the relevance (Does the event require attention or adaptive reaction?) or unexpectedness (Was

${ }^{1}$ Organismic subsystem (and their major substata are the following): Information processing (Central Nervous System CNS), Support (CNS, Neuro-Endocrine System, Autonomic Nervous System), Executive (CNS), Action (Somatic Nervous System), Monitor (CNS), from Sander, Grandjean \& Scherer (2005, [19]). the event predicted from past knowledge?).

On the other hand, one has to cope with the situation appraised before by using coping strategies. These different strategies offer a great range of possibilities, from the perfect control of the situation until the total resignation, when facing the problem. The coping outcome alters the person-environment relationship not only by modifying the environment itself related to the problem, but also by changing the interpretation and willing through emotional aspects.

In order to represent the information about the situation, Gratch \& Marsella 10] use causal maps. In the following scenario (figure 2), an oncologist, Dr. Tom, is supposed to help an eleven-year-old boy, Jimmy, for his stage 4 inoperable cancer, either by giving him morphine (which relieves the pain but hastens death) or leaving him suffer (and letting him prolong his life). A causal map (see figure 21) represents the past and present situations, as well as the possible decisions to make and their expected consequences.

This causal map can evolve with the modification of the parameters. For example, $U_{\text {Jim }}$ is how Dr. Tom appreciates Jim's desirability for the corresponding event. This value can be updated after the coping process, dealing with emotional aspects. Once Dr. Tom re-appraises the consequences of his decision (by decreasing the probability parameter of the "Death hastened" event), he accepts to give Jim morphine, following Jim's mother request.

However, the major problem when using this technique is the storage of the information taken from the environment. In fact, we have two options.

The first option is to put all the information we need explicitly on the object to be evaluated. For instance, if an individual is watching a photograph of his wife and kids, the variables indicating pleasantness or pride are to be described on the photograph. With this method, each object in the environment is clearly identified as pleasant or mysterious or annoying, etc. The implementation is therefore easier, and the possibility of interacting with the emotional representation of the object is hence trivial. The main problem is a lack of flexibility, especially if more than one individual has to evaluate the same object.

The second option is the internal storage of the objects data, directly into the brain, using a memory strategy (Tulving et al., 1972 [29]). With this technique, memory is divided into several categories, each of which stores different kind of information. On the one hand, the longterm memory system is composed of the episodic memory (i.e. it refers to knowledge of episodes and facts that can be consciously recalled and related) and the semantic memory (underlying absolute knowledge and language; semantic memory is context-independent). On the other hand, the short-term memory, also known as working memory stores the current context-related data. For each of the above options, emotion is supposed to 


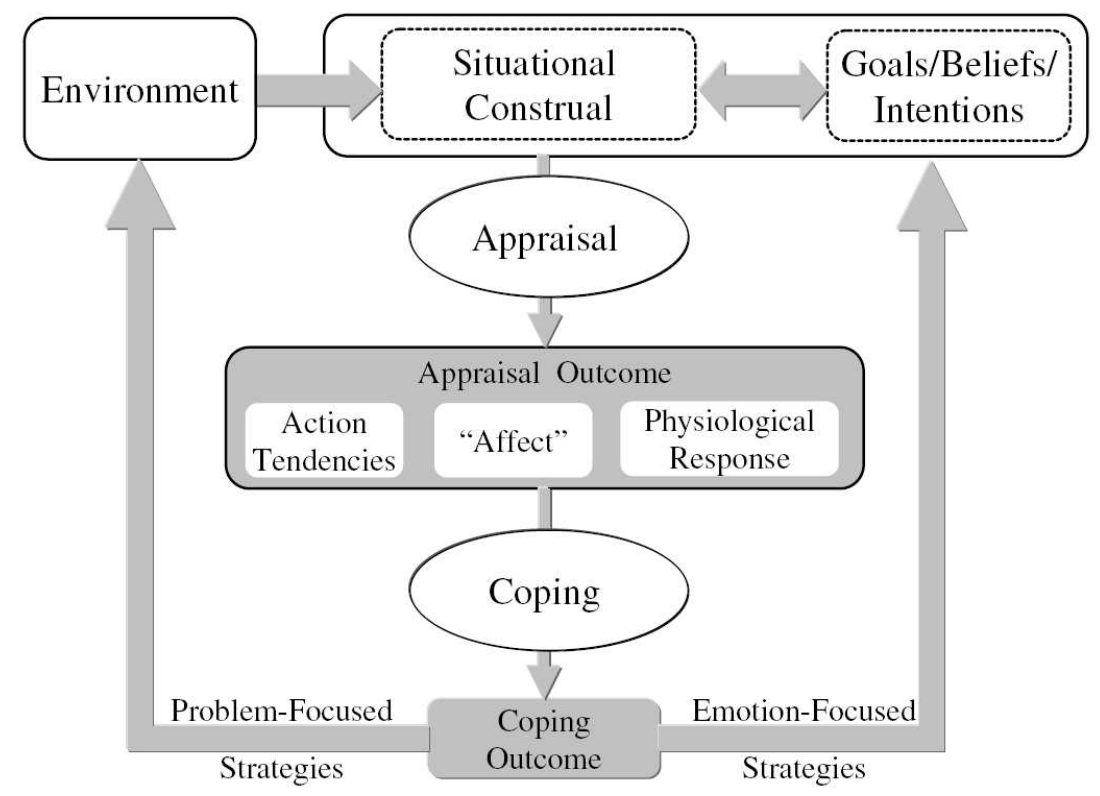

Figure 1: The cognitive-motivational-emotive system. Adapted from Smith an Lazarus (1990, [26]).

be triggered from the appraisal processes. Indeed, the evaluation activity requires knowledge, and emotion is part of the memory processes of encoding, storage and retrieval (Tulving \& Thomson, $1973[30]$ ). For modelling purpose, we assume that memory is split into three categories :

- The semantic or factual memory which stores the global knowledge of the world and the information considered to be facts, like "Paris is the capital of France".

- The episodic or autobiographical memory which contains the personal events that happened in an individual's life. This type of memory is strongly linked with a spatio-temporal context.

- The working memory is the current dynamic representation that an individual has in mind when solving a particular problem.

Each time a memory element is encoded (i.e. added into the brain), it is stored along with the current emotional learning context $e_{t_{0}}$. Later on, when the information is required and must be found in the memory, the current emotional context $e_{t}$ will be compared to the former emotional learning context related to the required memory item. If the old emotional context equals the current one (i.e. if $e_{t_{0}}=e_{t}$ ) the retrieval mechanism will be facilitated. On the contrary, if the two values are different $\left(e_{t_{0}} \neq e_{t}\right)$, the retrieval process will be made more difficult.

\section{THE "CASCADES" PROBLEM}

The "Cascades" problem is a puzzle-like situation in which the goal is to fill up the grid with numbers according to the following instruction: "Each box contains the sum of the numbers situated above it. Look for the missing numbers in the grid".

The initial state and the first solving step are presented hereafter (figure 3).

Ten-year-old children will be invited to solve the problem. In order to study how the emotions are elicited over the course of the problem, emotional manifestations will be recorded without interruption during the problem-solving activity. In line with the work of Clément \& Duvallet (2007 [6]), we will focus on two kinds of response components: the physiological - electrodermal activity - and the expressive - facial expressions components.

Although the definition of emotions remains controversial, some researchers distinguish emotions and other related notions as mood or personality traits on the basis of their behavioural time course and intensity: emotions are defined as short-lived behavioural dispositions, moods are of longer duration and lower intensity, while personality traits reflect relatively stable behavioural tendencies.

Nevertheless, it is generally assumed that emotions may be evaluated by three kinds of responses: the physiological responses which the electrodermal activity and the heart rate are the most widely used, the expressive responses including facial, vocal, gestural and postural expressions and the subjective responses based in part on verbal report (see Bauer, 1998 [2]; Boehner, DePaula, 


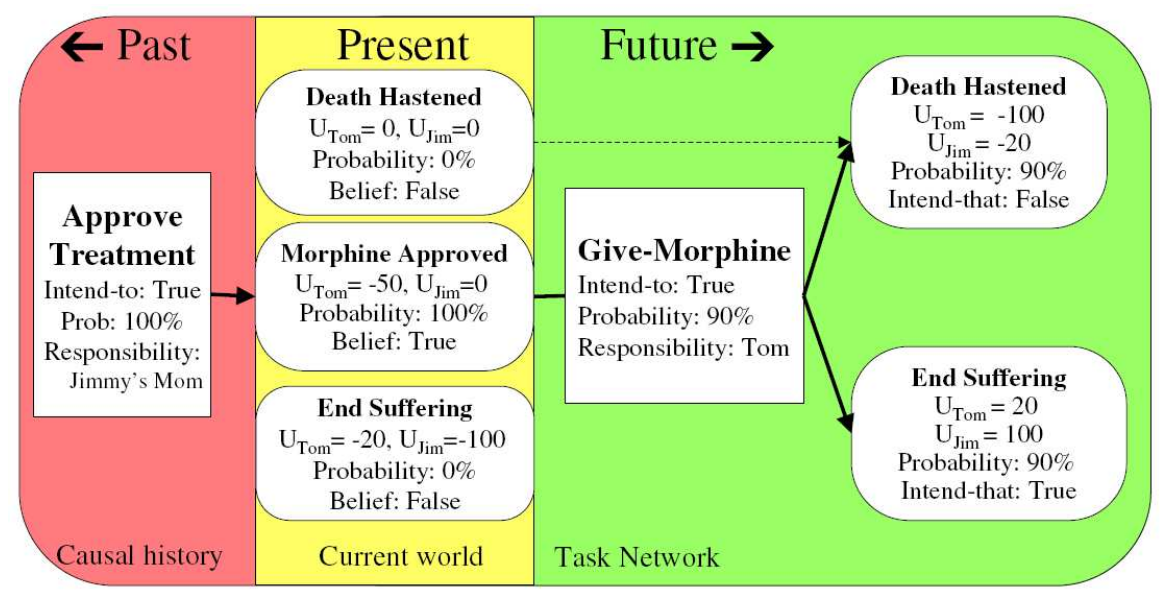

Figure 2: Dr. Tom's causal interpretation at the end of the scenario.
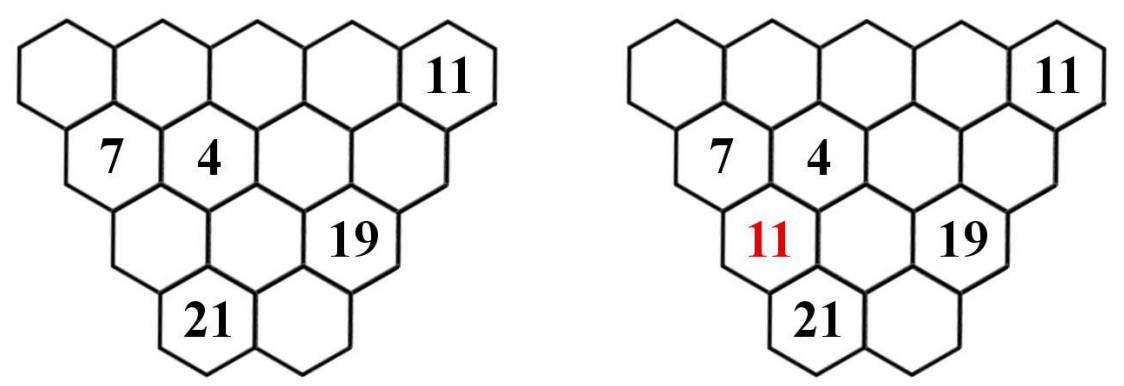

Figure 3: The "Cascades" initial grid and the first solving step.

Dourish, \& Sengers, 2007 [4], for critical reviews).

Concerning the physiological component, and in particular the electrodermal activity, the study of Pecchinenda and Smith (1996) provides psychological significance of spontaneous skin conductance activity. In that work, participants were given to solve a set of anagrams which difficulty was manipulated by both the objective difficulty (easy, moderately, difficult, extremely difficult) and the amount of time available to solve the problems (30 vs. 120 seconds). The authors demonstrate that the skin conductance activity during problem solving is correlated to the appraisals of coping potential: in a difficult problem, appraisals of coping potential based on self-report are especially low and produce selective disengagement of the task, yielding reduced skin conductance activity. The spontaneous electrodermal activity is interpreted as reflecting task engagement (Pecchinenda, 2001 [17]).

Moreover, the results of Clément and Duvallet (2007 [6]) support the idea that skin conductance activity is a convergent measure of appraisal-related processes and that facial expressions reflect the appraisals of the events according to their conduciveness for the goal (Kaiser \& Wehrle, 2001 [12]; Scherer, 1999 [21]; Smith, 1991 25]; Smith \& Scott, 1997 [28]).
THE APPRAISAL-COPING MODEL

The appraisal-coping model adaptation to the "Cascades" problem (see figure 4) allows us to analyse in a more accurate way the children's cognitive emotional activities. The appraisal step deals with the evaluation and the prediction of the plan selected by the child in order to solve the problem. According to this appraisal step, the child will fill in a hexagon, following his selected plan, or correct a previous result, or if the appraisal step leads to a bad evaluation, he will change his plan (we observe that the exercice instructions are interpreted in many different ways, especially for children with school difficulties).

The coping strategy is the actual decision a child will take with respect to his previous choices. The coping process is usually accompanied by an emotional reaction which depends on the appraisal consequences. For instance, if the child decides to reinforce his strategy, his emotional state will be positive. On the contrary, if he continually changes his plans, the situation will end up with a progressive disengagement for the task. 


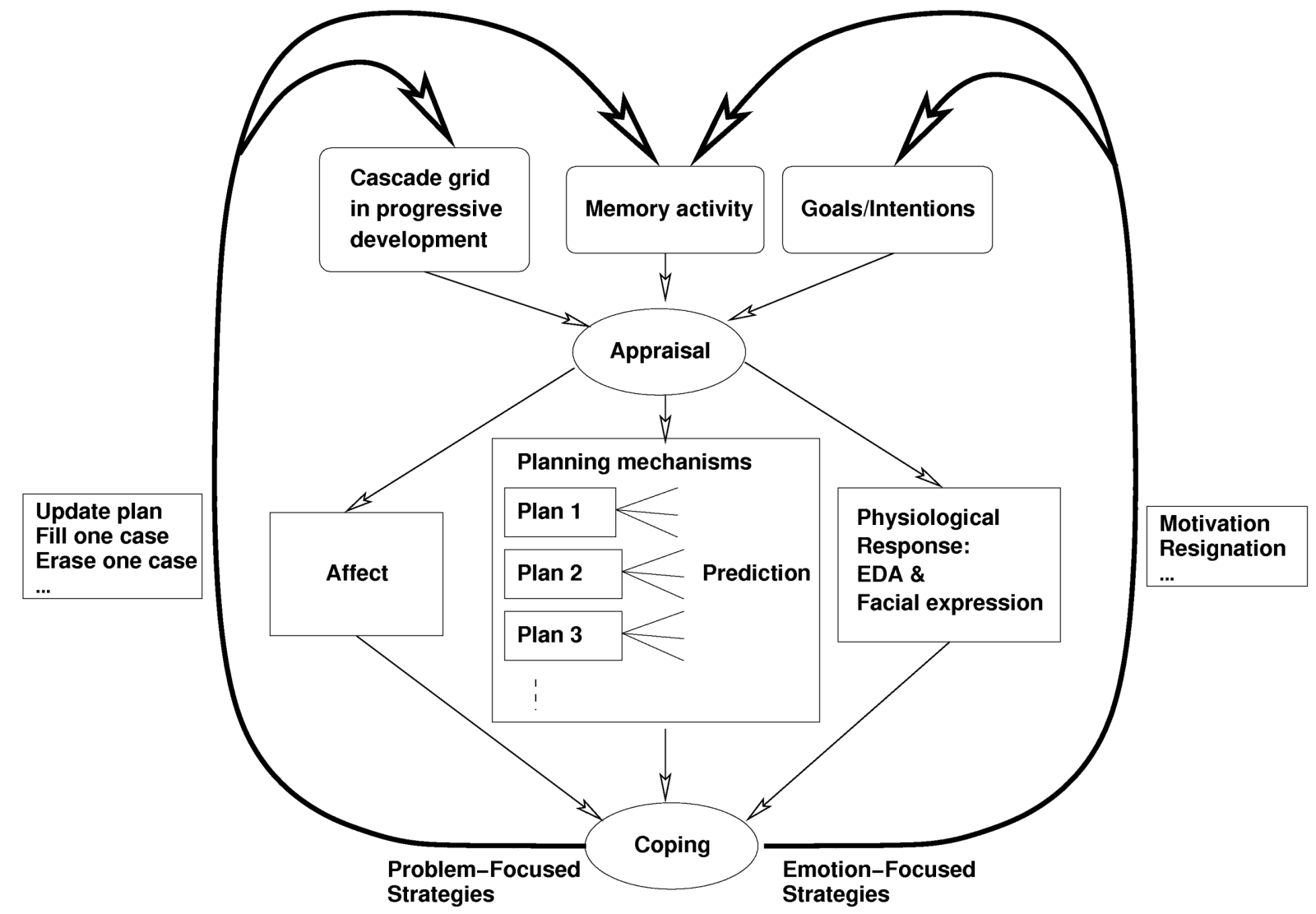

Figure 4: The appraisal-coping model applied to the "Cascades" problem.

\section{CONCLUSION AND PROSPECTS}

Contrary to the classical models which study cognition in a "cold" way, independently from any emotional process, we are now trying to unravel the mysteries underlying the emotion-cognition interaction. This new challenge makes researchers produce a new generation of cognitive models, based on more accurate systems, such as the appraisal-coping approach.

The multidisciplinary work carried out so far allows us a better understanding of emotion mechanisms, by bringing out two complementary approaches:

- The produced model aims to analyse the experimental data.

- The experimental data come to strengthen or question the existing model.

As a future work, the strategies selected in the coping process are to be examined more precisely, in order to extract cognitive-emotional individual profiles, and especially when it comes to help pupils with school difficulties.

\section{REFERENCES}

[1] S. Baudic and G.H.E. Duchamp. Emotions: theoretical models and clinical implications. In European Simulation and Modelling Conference '2006, 2006.

[2] R.M. Bauer. Physiologic measures of emotion. Journal of Clinical Neurophysiology, 15:388-396, 1998.

[3] A. Bechara, H. Damasio, and A.R. Damasio. Emotion, decision making and the orbitofrontal cortex. Cerebral Cortex, 10:295-307, 2000. http://cercor.oxfordjournals.org/cgi/content/full/

[4] K. Boehner, R. De Paula, P. Dourish, and P Sengers. How emotion is made and measured. International Journal of Human-Computer Studies, 65:275-291, 2007.

[5] E. Clément. La flexibilité représentationnelle. Mémoire de HDR - Université de Rouen, 2007.

[6] E. Clément and D. Duvallet. Emotions elicited by impasses and subgoal achievements in problemsolving. In CEM 07, Cognition, Emotion and 
Motivation International Congress, Hammamet, Tunisia, 2007.

[7] D. Denton. The Primordial Emotions: The Dawning of Consciousness. Oxford University Press, USA, 2006.

[8] P. Ekman. Expression and the nature of emotion. In K.R. Scherer and P. Ekman, editors, Approaches to emotion. Erlbaum, Hillsdale, NJ, 1984.

[9] N. Frijda. The Emotions. Cambridge University Press, Cambridge, 1986.

[10] J. Gratch and S. Marsella. A domain-independant framework for modeling emotion. Cognitive Systems Research, 5:269-306, 2004.

[11] C.E. Izard. The face of emotion. Appleton (Century/Crofts), New York, 1977.

[12] S. Kaiser and T. Wehrle. Facial expressions as indicators of appraisal processes. In K.R. Scherer, A. Schorr, and T. Johnstone, editors, Appraisal processes in emotion: Theory, methods, research. Oxford University Press, New York, 2001.

[13] R.S. Lazarus. Thoughts on relations between emotion and cognition. The American Psychologist, 37:1014-1019, 1982.

[14] R.S. Lazarus. Emotion and Adaptation. Oxford University Press, New York, 1991.

[15] K. Mahboub. Modélisation des processus émotionnels dans la prise de décision. Master's thesis, Université du Havre, France, 2006.

[16] K. Mahboub. Simulation of emotional processes in decision making. In European Simulation and Modelling Conference '2006, 2006.

[17] A. Pecchinenda. The psychophysiology of appraisals. In K.R. Scherer, A. Schorr, and T. Johnstone, editors, Appraisal processes in emotion: Theory, methods, research. Oxford University Press, New York, 2001.

[18] A. Pecchinenda and C.A. Smith. The affective significance of skin conductance activity during a difficult problem-solving task. Cognition and Emotion, 10:481-503, 1996

[19] D. Sander, D. Grandjean, and K.R. Scherer. A systems approach to appraisal mechanisms in emotion. Neural Networks, 18:317-352, 2005.

[20] K.R. Scherer. On the nature and function of emotion. a component process. In K.R. Scherer and P. Ekman, editors, Approaches to Emotion, pages 293-317. Erlbaum, Hillsdale, NJ, 1984.
[21] K.R. Scherer. Appraisal theories. In T. Dalgeish and M. Power, editors, Handbook of cognition and emotion. Wiley, Chichester, 1999.

[22] K.R. Scherer. Appraisal considered as a process of multi-level sequential checking. In K.R. Scherer, A. Schorr, and T. Johnstone, editors, Appraisal processes in emotion: Theory, methods, research. Oxford University Press, New York, 2001.

[23] K.R. Scherer and M. Peper. Psychological theories of emotion and neuropsychology research. In F. Boller and J. Grafman, editors, Handbook of Neuropsychology, volume 5: Emotional behavior and its disorders, pages 17-48. Elsevier, Amsterdam, 2001.

[24] K.R. Scherer, A. Schorr, and T. Johnstone. Appraisal processes in emotion: Theory, methods, research. Oxford University Press, New York, 2001.

[25] C.A. Smith. The self, appraisal, and coping. In C.R. Snyder and D.R. Forsyth, editors, Handbook of social and clinical psychology: The health perspective. Pergamon, New York, 1991.

[26] C.A. Smith and R.S. Lazarus. Emotion and adaptation. In L.A. Pervin, editor, Handbook of personality: Theory and research, pages 609-637. Guilford, New York, 1990.

[27] C.A. Smith and R.S. Lazarus. Appraisal components, core relational themes, and the emotions. Cognition and emotion, 7:233-269, 1993.

[28] C.A. Smith and H.S. Scott. A componential approach to the meaning of facial expressions. In J. Russel and J.M. Fernandez-Dols, editors, The psychology of facial expression. Cambridge University Press, Cambridge, 1997.

[29] E. Tulving. Episodic and semantic memory. In E. Tulving and W. Donaldson, editors, Organisation of memory, pages 381-403. Academic Press, New York, 1972.

[30] E. Tulving and D.M. Thomson. Encoding specificity and retrieval processes in episodic memory. Psychological Review, 80:352-373, 1973. 